Communications in Information Literacy

Volume 6 | Issue 1

Article 4

$12-6-2012$

\title{
Information Literacy on the Web: How College Students Use Visual and Textual Cues to Assess Credibility on Health Websites
}

Katrina L. Pariera

University of Southern California, pariera@usc.edu

Follow this and additional works at: https://pdxscholar.library.pdx.edu/comminfolit

Part of the Information Literacy Commons

Let us know how access to this document benefits you.

\section{Recommended Citation}

Pariera, K. L. (2012). Information Literacy on the Web: How College Students Use Visual and Textual Cues to Assess Credibility on Health Websites. Communications in Information Literacy, 6 (1), 34-48.

https://doi.org/10.15760/comminfolit.2012.6.1.116

This open access Research Article is distributed under the terms of the Creative Commons AttributionNonCommercial-ShareAlike 4.0 International License (CC BY-NC-SA 4.0). All documents in PDXScholar should meet accessibility standards. If we can make this document more accessible to you, contact our team. 


\title{
INFORMATION LITERACY ON THE WEB
}

\section{How College Students Use Visual and Textual Clues to Assess Credibility on Health Websites}

Katrina L. Pariera

University of Southern California

\begin{abstract}
One of the most important literacy skills in today's information society is the ability to determine the credibility of online information. Users sort through a staggering number of websites while discerning which will provide satisfactory information. In this study, 70 college students assessed the credibility of health websites with a low and high design quality in either low or high credibility groups. The study's purpose was to understand if students relied more on textual or visual cues in determining credibility and to understand if this affected their recall of those cues later. The results indicate that when viewing a high credibility website, high design quality will bolster the credibility perception, but design quality will not compensate for a low credibility website. The recall test also indicated that credibility does impact the participants' recall of visual and textual cues. Implications are discussed in light of the Elaboration Likelihood Model.
\end{abstract}




\section{INTRODUCTION}

Faced with an abundance of information from a host of diverse sources, Web users must learn to sift through a large number of potential resources and determine which sources will provide satisfactory information. The Web is a unique environment for users trying to determine which information to believe because traditional credibility assessments often do not apply online. Understanding credibility on the Web is increasingly important as it has become the medium of choice for finding information for $92 \%$ of adult U.S. internet users (Pew Internet and American Life Project, 2011a). Since people turn to the Web for information and find a staggering amount of it, it is important to understand how they evaluate and determine the credibility of the information they find.

Information literacy is about accessing and analyzing information, and Web literacy is a subset of information literacy which involves applying those skills online and being able to recognize obscured intent and pay attention to non-textual features (Burke, 2002; Kuiper, Volman, \& Terwel, 2009; Sorapure, Inglesby \& Yatchisin, 1998). In other words, Web users must sort through both textual and visual cues to determine the credibility of information online. One of the most important areas for determining the credibility of online information is health.

In the United States $80 \%$ of Internet users (or $60 \%$ of the adult population) look for health or medical information online, (Pew Internet and American Life Project, 2011b) making this a particularly important area of focus for web literacy. In a report from the International Federation of Library Associations and Institutions health, care professionals emphasized that the increase of health related self-help behaviors online has created a greater need for people to develop information literacy skills (Devotion-Garner, 2005). Moreover, when it comes to health issues, relying on information that lacks credibility has the potential to lead not only to poor knowledge but poor health choices, making health a unique area of importance for information literacy.

Early research on how people assess credibility defined the concept simply as trustworthiness, expertise and believability (Hovland, Janis, \& Kelley, 1953), terms which are still used by credibility researchers today (Fogg, et al., 2003). For a highly visual and dynamic medium like the Web, evaluations of credibility may be more about how a site looks than what it says. A study by Fogg and colleagues found that many U.S. adult Internet users felt that a good design look was the most important factor for deciding if a website is credible (2002). The majority of participants in this study mentioned design look as a factor (46\%), while factors which may have been expected to play a higher role were not mentioned as frequently, such as company motive, accuracy of information, and advertising. Rains and Donnerstein Karmikel (2009) found that website structure, meaning the number of links and menus, contributed to credibility perceptions for health websites.

Walther, Wang and Loh (2004) looked at how credibility was rated when visual advertisements were inserted on different websites with different domains. They found that the presence of advertisements had a negative impact on credibility when they were on websites in the .org domain but had a positive impact on websites with .com and .edu domains. This research emphasizes the complicated nature of assessing credibility online and the number 
of elements which play a factor in these evaluations.

Studies in audience credulity focus on characteristics of the audience that affect their subjective assessments of credibility. Having heavy involvement with an issue has a strong effect on perceptions of credibility (Gunther, 1992; Stamm \& Dube, 1994), as does heavy use of the medium in question (Johnson, Kaye, Richard \& Wong, 2008; Kiousis, 2001). Studies looking at the message itself have found that credibility can be affected by disorganization and nonfluency in messages (McCrosky \& Mehrley, 1969), message intensity (Hamilton \& Stewart, 1993), and the writing quality and quantity, (Corrigan \& Stephens, 2007; Jackson, 1992; Slater \& Rouner, 1996).

It is not only important to understand how people decide whether or not information is credible but also to understand how that affects their memory of that information. The research suggests that the addition of visual cues to a text actually alleviates some of the cognitive load in processing the message making it easier to recall. Visual mediums may be easier to remember than print-only mediums (Fox, et. al., 2004; Kools, Van de Wiel, Ruiter, \& Kok, 2005; Van der Molen and Klijn, 2004), and congruency of those images also plays a role in memory (Moore, Stammerjohan \& Coulter, 2005). This is especially pertinent to our understanding of recall on the Web, since most content on the Web is accompanied by images.

Credibility is a tool for persuasion. If we believe information is credible we are more likely to internalize the information and act on it. Petty and Cacioppo's ElaborationLikelihood Model (1986) explains that there are two routes to persuasion. The central route involves more thoughtful consideration of the information and takes place when the person has the time and incentive to scrutinize an argument. The peripheral route involves simpler cues that are not relevant to the issue, such as source attractiveness, and these are processed in a relatively less complicated manner. Petty and Cacioppo claim that the extent to which people process a message centrally or peripherally varies based on the individual and the situation. They argue that as motivation or ability to evaluate a message decreases, the peripheral route becomes the primary determinant of persuasion. Conversely, people are more likely to use the central route when they have greater stake in the argument, are knowledgeable about it, and are motivated and able to process the information. They also argue that persuasion that occurs through the central route will be more enduring and be a greater prediction of behavior changes, since it involves more elaborate consideration of the information.

Some studies have looked at how the Elaboration Likelihood Model (ELM) can be applied online. Karson and Korgaonkar (2001) tested participants to see if involvement affected their processing of online information. They found that when browsing websites the peripheral cues had little effect on brand attitudes. However, a study by Freeman and Spyridakis (2004) found that participants with high involvement in a topic paid more attention to central cues such as presence of an address, links to further information, and contact information.

Some studies have looked at how people feel about using the Web for information seeking. A 2005 study found that 38\% of students aged 12-17 trusted most of the information they found online, while only $10 \%$ were skeptical about it (Livingstone, 
Bober, \& Helsper). They also found that people who consider themselves beginners in Internet use are more distrustful of it than those who consider themselves experts. Agosto's 2002 study found that teenagers used perceived quality of graphic content and level of interactivity to measure credibility, and that most teens generally assumed that websites were accurate. Bird, McInerney, and Mohr (2010) observed college students in a naturalistic websurfing setting and found that writing quality was the most important factor but how user-friendly a website is also plays a large role in credibility assessments. Graphics and style were less important.

Brem, Russell and Weems (2001) introduced 81 high-school students to a set of evaluation criteria for websites and then tested their ability to use these evaluations on a set of websites of varying credibility. Students tended to focus on the author's credentials, goodness of motives and amount of details in order to decide if a website was credible or not. Overall they found that introducing the evaluation criteria to the students was somewhat effective, but that it did not always help them make thoughtful evaluations.

While college students are often taught that format is a cue for credibility, specifically that books and peer-reviewed journals are considered more credible formats (Mark, 2011), it is not clear how this applies to online materials since the line between formats may be blurred. Other traditional methods of determining source credibility have been textual, such as author, date of publication, edition, and publisher. On the Web, however, these conventions have changed and this information is not always easy to find. When these textual and format cues are not available, it is possible users may turn to visual cues, such as design quality, to decide if a website is credible or not. Websites that have the resources to make well designed pages may be seen as more legitimate and therefore more credible. These visual cues may be the source of the credibility assessment when there is a dearth of traditional textual cues or may supplement it when textual cues are provided.

This study offers a unique perspective on the issue because websites were viewed in a controlled environment. Websites were designed specifically for the study in order to compare specific features within and between experimental groups. This study also provides a unique perspective on ELM because involvement is expected to be low for the participants. The study used websites related to health issues since health information is such an important place to apply information literacy skills. In order to keep involvement low for our participants, we focused on the topic of childhood illness since college students were not expected to have a large personal or professional interest in that health topic. Understanding whether students focus on central or peripheral cues will shed some light on how the ELM model may be applied to persuasion online. While the previous research has shown that both visual and textual cues play a large role in how a message is perceived, it is not yet clear how these cues compete for or supplement credibility perceptions and how well they are recalled after the evaluation has been made.

The purpose of this research was to find out whether students rely more on visual or textual cues when they are evaluating the credibility of a health-related website. Perceptions of website credibility were compared between those with an appealing design quality and those with a poor design quality. Perceptions were also compared 
between websites with traditional textual indicators of credibility to those with low textual indicators of credibility. Furthermore, the study measured whether or not these credibility perceptions affect how well participants recall information. These results will help our understanding about how people, especially college students, assess credibility, and in turn how they develop information literacy skills as heavy users of the Internet. The research will answer the following questions:

$R Q_{1}$ : Do participants rely more on textual or visual cues to assess the credibility of information found on health websites?

This question is answered by comparing participant ratings of perceived credibility for websites with high design quality to websites with low design quality. Another analysis compared participants' ratings of credibility for websites which have high traditional credibility cues in the form of textual cues (author name, author credentials and affiliation, date of publication, and references) and which have low traditional credibility cues (no author name, no author credentials nor affiliation, no date of publication, no references, and a commercial advertisement).

To take the study one step further, recall of these textual and visual cues were tested, in order to answer the following questions:

$R Q_{2}$ : Controlling for design, do credibility assessments impact participant recall of visual and textual cues?

$R Q_{3}$ : Controlling for credibility, does design quality impact participant recall of visual and textual cues?

Questions two and three were answered by analyzing the results of a memory test one week after the participants viewed the websites. Recall of visual and textual cues were counted and compared from the high design websites to the low design websites. Question three was also tested by comparing the results of a memory test one week after students viewed the websites. Recall of visual cues was recorded and compared between those from participants in the high credibility group and those in the low credibility group.

\section{METHOD}

\section{Participants}

The participants for this study were recruited from a group of 75 undergraduate students enrolled in a psychology course at a private university in the eastern United States. Although participants were enrolled in a psychology course, they came from a variety of majors including psychology, marketing, art history, biology, economics and others. Participation in the study was voluntary. Students received extra credit for participating, but were also given an alternative option for extra credit if they did not wish to participate in the study. Students were told that they would be required to have uninterrupted Internet access for approximately 20-30 minutes to complete the first part of the study and another 20 minutes of uninterrupted Internet access to complete the second part of the study one week later. Of the 75 students enrolled in the course, 71 of them signed and returned informed consent forms.

\section{Procedures}

Within evenly distributed gender groups, participants were randomly assigned to one of two conditions: low credibility or high credibility. Participants in each group compared two websites with controlled variables. A total of four websites served as 


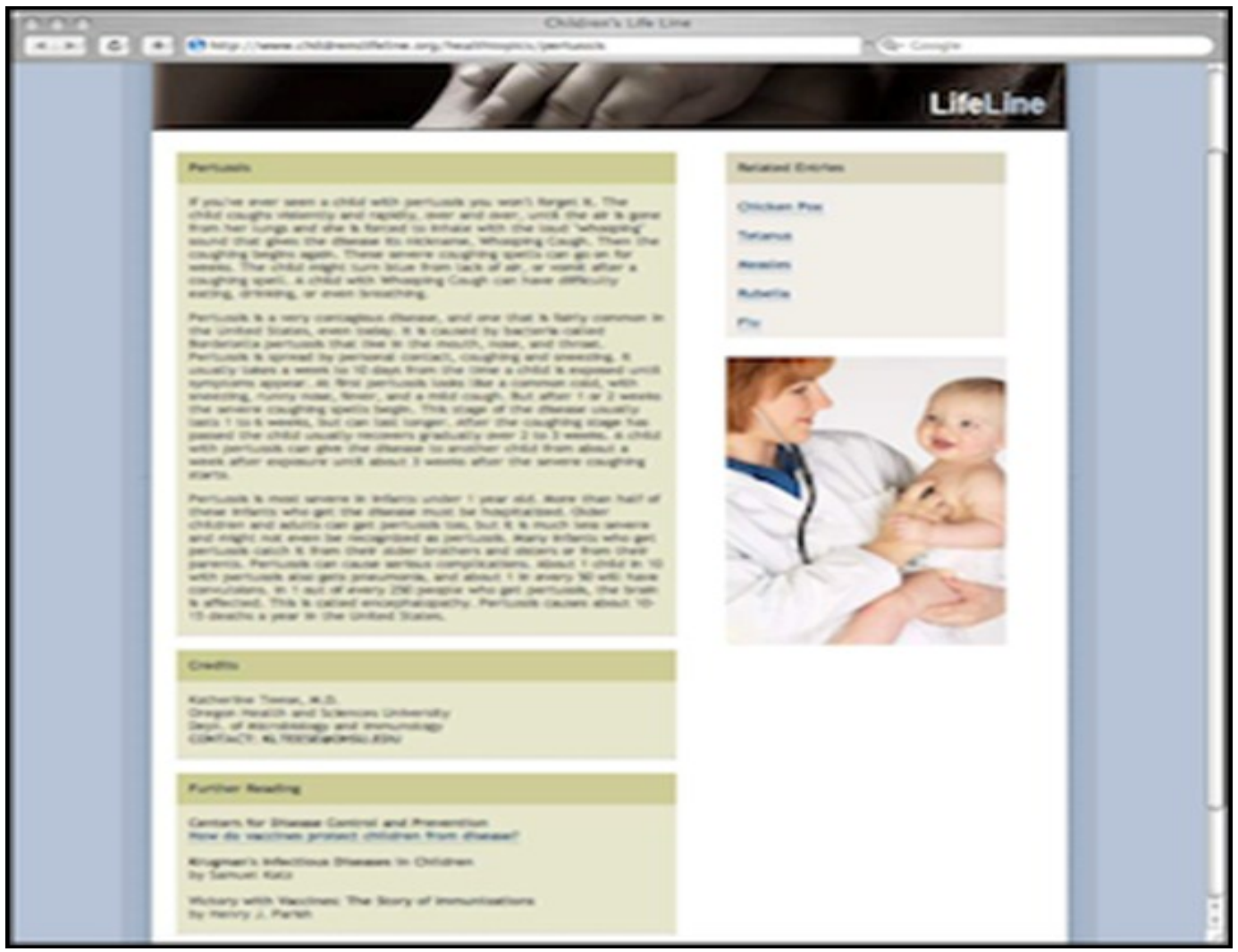

FIGURE 1 - High Credibility, High Design Quality

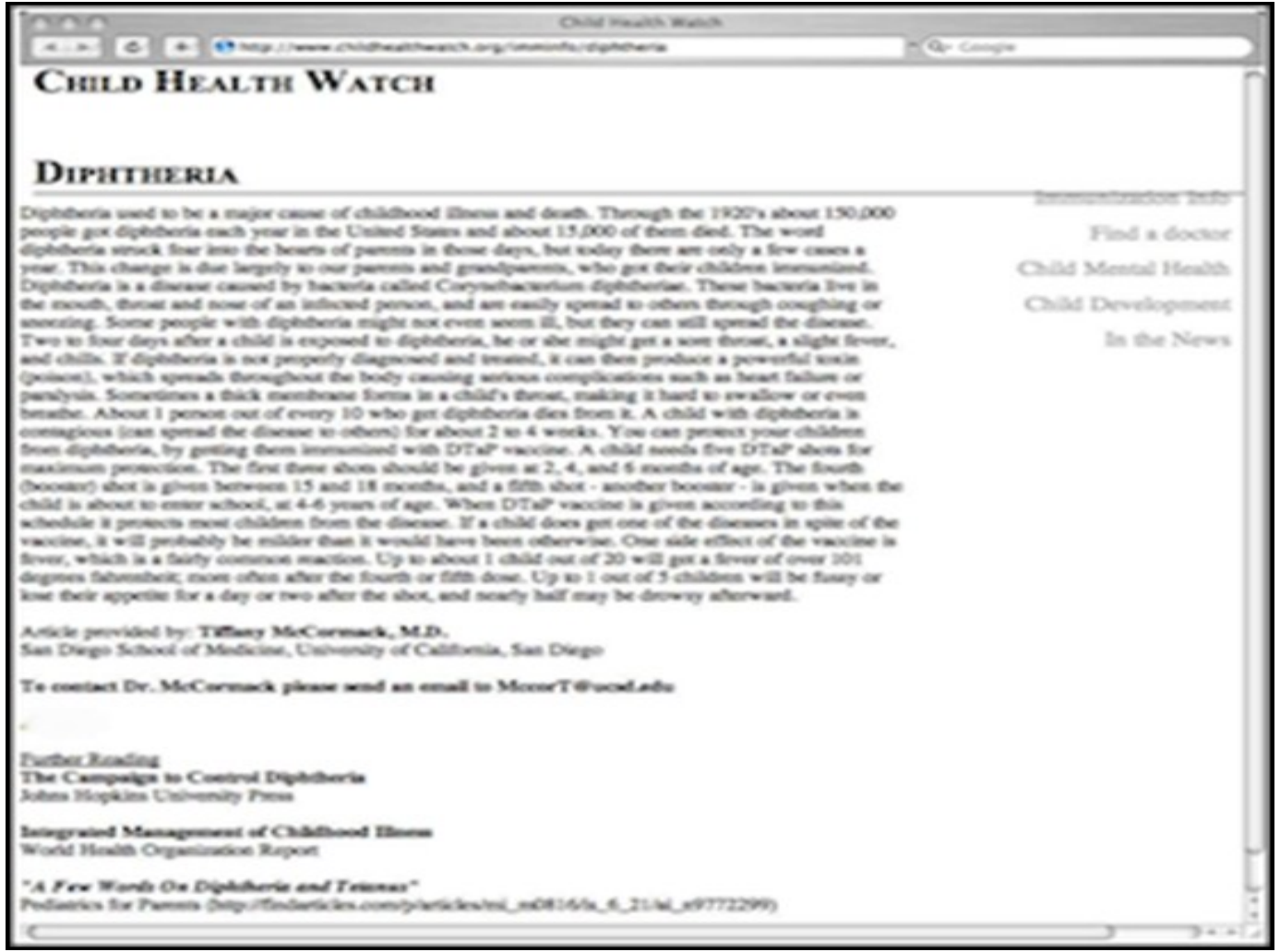

FIGURE 2 - High Credibility, Low Design Quality 


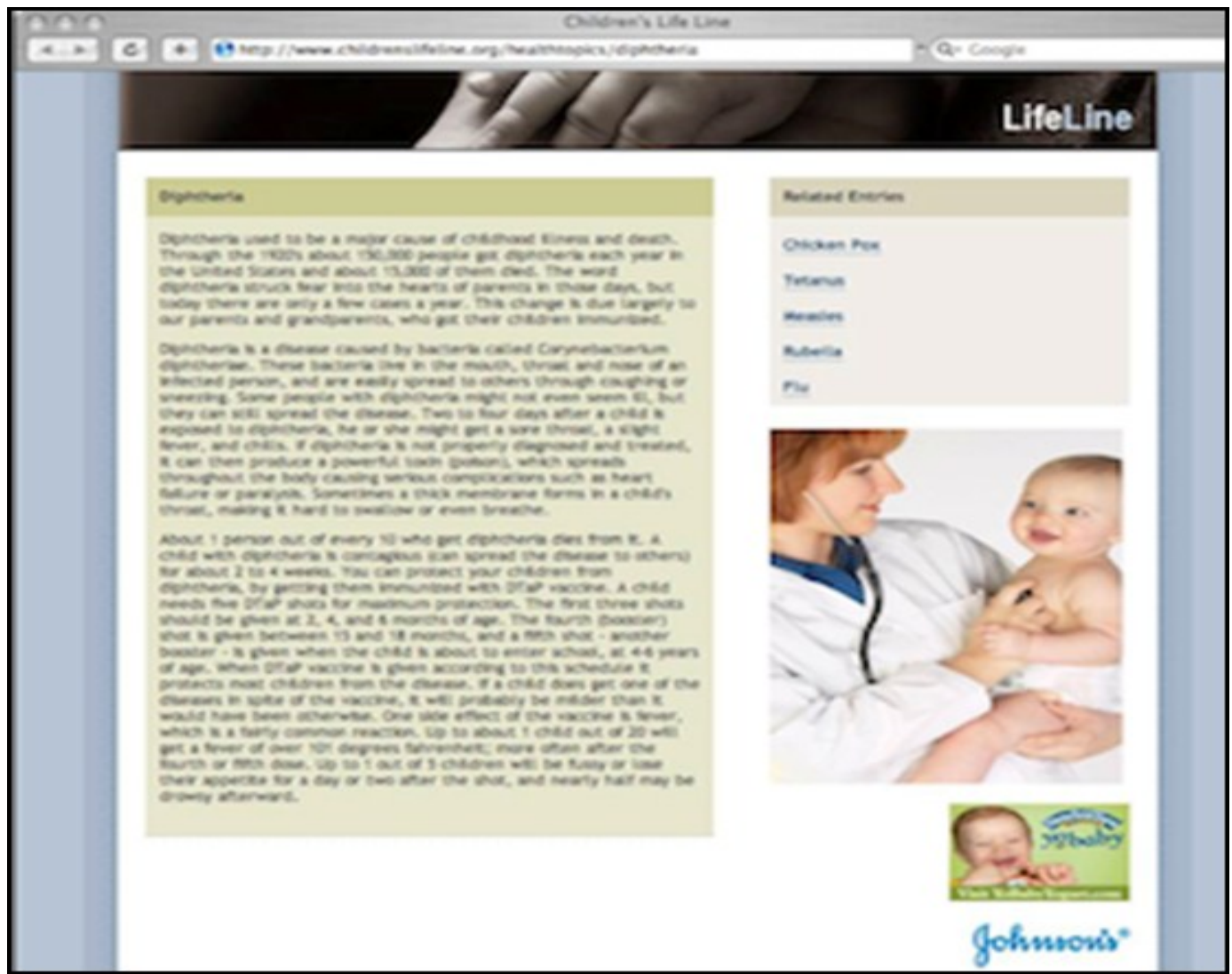

FIGURE 3 - Low Credibility, High Design Quality

\begin{tabular}{|c|c|}
\hline 800 & Oild Heath Watch \\
\hline
\end{tabular}

\section{Child Health Watch}

\section{Pertussis}

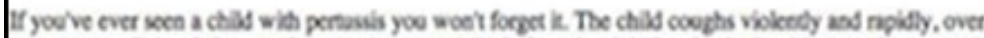

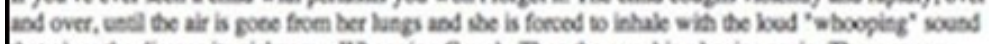
hat gives be discase its nickname, Whooping Coogh. Then be cooghing begias agala. These svere coughing spells cas go oe for wocks. Toe chily might wim bloe froe lack of at, or vomit afer a coopting

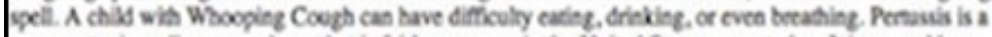

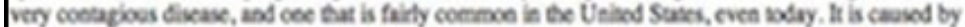

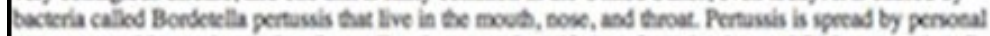
coetact, cooghing and socezing. It owally wies a woek to 10 days froen the time a child is exposed und

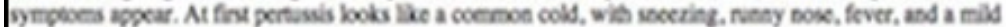
oouph. But aher 1 or 2 woeks the severe coophing spelis begie. This dape of Ae discase weally lase in 6

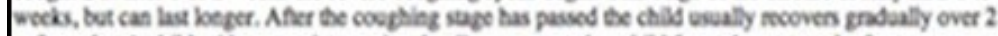

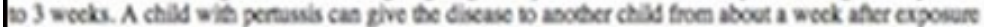
Fed about 3 weeks afer be severe cooghing stars. Penausis is most svere in infins under 1 year old.

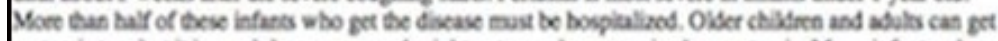
pertousis too, bot is is moch kus severe and might not even be rocognibod as pereusis. Many infuets who

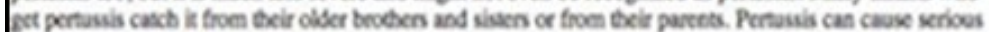

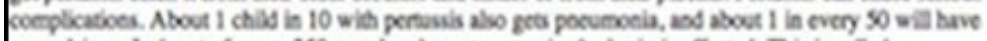
coevulibes. In 1 cot of every 250 people wbo get pertusus, the brain is affocied. This is callod. escephabopaty. Fentubis casess about 10-15 deatis a year in be Unind Sutes.

Find a doctot

Child Mental Health

Child Development

In the News

Feel better.

TYLENOL

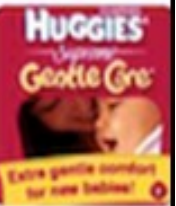

FIGURE 4 - Low Credibility, Low Design Quality 
the independent variables (see Figures 1-4). The websites were created specifically for the study and screenshots of them were used in the questionnaires. Participants in each group saw one low design quality website and one high design quality website. Both groups saw the same two websites, but the high credibility group saw websites which featured textual cues including author name, author credentials and affiliation, date of publication, references, and no advertisements. Both high and low credibility websites had an .org suffix because pilot testing suggested this would be a strong credibility indicator and we wanted participants to look for more cues. Participants in the low credibility group saw websites with no author information, no date of publication, and no references. These websites also had advertisements on them (for Tylenol and Huggies or Yo Baby and Johnson's). These decisions were based on prior research which found that credibility perceptions are affected by advertisements (Eastin, Yang, \& Nathanson, 2006; Fogg, et. al, 2001; Walther, Wang \& Loh, 2004), authors' credentials and citations (Fogg, et. al, 2001) and source information (Freeman and Spyridakis, 2004). The high design quality page had a more professional look, was organized, and had a complementary color scheme. The low design quality page was all white and the text was less organized.

The websites had short articles on the childhood illnesses pertussis and diphtheria, and the content of the articles was the same regardless of which credibility group they were in. These articles were selected because it was assumed the students would have little prior knowledge or involvement with infant illnesses and we wanted involvement to remain low. The articles were actually copied from the Centers for Disease Control website and were written for a general audience which results in a tone that was neither too technical nor too informal. The topics for the websites were randomly reversed to control for order effects.

Prior to administering the study, a separate group of eight students and professors were asked to rate all four websites in order to gather consensus that the design quality and credibility levels were accurately described. The websites were tweaked until inter-rater reliability for low and high credibility and low and high design quality was $100 \%$. The websites were then shown to a group of five people who also had $100 \%$ inter-rater reliability for low and high credibility and low and high design quality.

Study participants were emailed a link to an online survey with instructions to look at a screenshot of a website, read the article on the website, and rate its credibility. After viewing the first website, the process was repeated with the second website. At the end of the questionnaire participants were reminded that they would be emailed a link to the second part of the study one week later and asked not to do any additional reading about the topics nor discuss them with other people.

The second questionnaire was administered one week later via an email with a link to the online survey. The participants were asked open-ended questions about which cues they remembered from the first website they had viewed the prior week. Participants were also asked to confirm that they did not discuss the article with anyone else. This process was then repeated for the second website. Participants were then asked to rate the visual appeal of each website.

\section{Credibility and Design Quality Scale}

The dependent variable, participants' 
credibility ratings, was measured with a brief version of Fogg, et. al.'s (2001) credibility measure, including statements such as "This article is believable," and "This article is trustworthy," asked on a sixpoint Likert scale from "Disagree Very Strongly" to "Agree Very Strongly." Two of the six questions from the original scale were eliminated because it was believed they would encourage the participants to look specifically for textual information ("How competent is the article?" and "How expert is the article?"). Design quality was assessed with a similar six-point Likert scale, with statements such as "This website is professional-looking," and "This website is visually organized." The credibility scale was reliable (Cronbach's alpha $=.869$ ) as was the design quality scale (Cronbach's alpha $=.901)$. Participants' ratings of design quality confirmed that these were low design quality $(M=3.25, S D=.78)$ and high quality design websites $(M=4.67, S D$ $=.78)$.

\section{RESULTS}

Participants were 70 undergraduates (23 males and 47 females) with an average age of $20.12(S D=1.19)$. Participants started using a computer at an average age of 7.75 years old $(S D=2.48)$ and using the Internet at an average age of $10.70(S D=1.91)$ years old. All participants in the study reported owning a computer and having a high speed or DSL connection in their homes. The data was assessed to look at means and standard deviations in order to check for outliers, and none were found.

$R Q_{1}$ : Do participants rely more on textual or visual cues to assess the credibility of information found on health websites?

To answer the first question, within-groups analyses for the high credibility and low credibility groups were conducted. As seen in Table 1, a paired samples t-test of the high credibility group revealed that the low design quality page had a lower rating of credibility $(M=4.28, S D=.62), \mathrm{t} 34=-2.21$, $p=.034)$ than the high design quality page $(M=4.48, S D=.60)$. A paired samples $\mathrm{t}$ test was also run with the low credibility group, but there was no significant difference $(p=.961)$ between the high design quality page $(M=4.18, S D=.70)$ and the low design quality page $(M=4.18$, $S D=.59)$.

A one-way ANOVA was conducted to compare the effect of design quality on credibility assessments in the high credibility and low credibility conditions. Design quality had no significant effect on credibility assessments in either the low credibility $[\mathrm{F}(1,68)=3.65, \mathrm{p}=.060]$ or high credibility groups $[\mathrm{F}(1,68)=.47, \mathrm{p}$ $=.495]$.

$R Q_{2}$ : Controlling for design, do credibility assessments impact participant recall of visual and textual cues?

A Pearson's chi-square test revealed that participants recalled the presence or absence of an author name significantly more in the high design quality group $\left(X^{2}(1)=8.00, p\right.$ $=.008)$. Participants also recalled the .org suffix significantly more in the high design quality group $\left(X^{2}(1)=12.69, p=.006\right)$. Significantly more participants in the low design quality group accurately remembered whether or not there were advertisements $\left(X^{2}(1)=6.59, p=.013\right)$.

$R Q_{3}:$ Controlling for credibility, does design quality impact participant recall of visual and textual cues?

A McNemar test was conducted within groups, which revealed that the percentage 


\section{TABLE 1 - DESCRIPTIVE DATA AND T-TEST COMPARISONS OF CREDIBILITY RATINGS BY WEBSITE}

\begin{tabular}{|c|c|c|c|c|}
\hline Variable & $n$ & $M$ & $S D$ & T-Test \\
\hline $\begin{array}{l}\text { High Credibility/ } \\
\text { High Design Quality }\end{array}$ & 34 & 4.48 & .60 & \multirow{2}{*}{$\begin{array}{l}\mathrm{t}(34)=-.2 .212, \mathrm{p} \\
=.034\end{array}$} \\
\hline $\begin{array}{l}\text { High Credibility/ } \\
\text { Low Design Quality }\end{array}$ & 34 & 4.28 & .62 & \\
\hline $\begin{array}{l}\text { Low Credibility/ } \\
\text { High Design Quality }\end{array}$ & 36 & 4.18 & .70 & \multirow{2}{*}{$\mathrm{t}(36)=-.049, p=.961$} \\
\hline $\begin{array}{l}\text { Low Credibility/ } \\
\text { Low Design Quality }\end{array}$ & 36 & 4.18 & .59 & \\
\hline
\end{tabular}

of participants in the high credibility group that remembered the .org suffix of the website differed significantly by design quality $(p=.031)$. In the low credibility group there was a significant difference in recalling the absence of an author name between the high design quality and low design quality websites $(p=.008)$.

\section{DISCUSSION}

The results of this study help increase our understanding and awareness of the processes students are using to determine credibility of health websites. Participants in the low credibility group ranked both websites as equally credible, despite the difference in design quality. Participants in the high credibility group, however, ranked the high design website as more credible. These results indicate students look first for traditional textual cues when assessing credibility, but those visual cues can be a supplemental factor after the textual cues are present.

Credibility also impacts the participants' recall of cues. When design quality was high, participants remembered the presence of an author name and the .org suffix. When design quality was low, they remembered whether or not there were advertisements.
When credibility was high participants recalled the .org status, but when credibility was low they remembered a lack of author name.

These results could be interpreted to mean that when a website has a professional design, people will look for the author's name and website suffix to assess credibility and may not care so much if there are advertisements. However, when a website is poorly made, the presence of advertisements will alert the user that the site may not be credible. When there are traditional textual cues present, people will look for the website's suffix, but when these cues are not present the lack of the author's name is what users notice.

Overall, this research shows that when viewing a website with traditional high credibility cues, a good design will bolster the credibility rating but cannot compensate for a lack of credibility cues. This indicates that textual cues (or lack of them) are more important than visual cues in determining website credibility, and the visual cues were only assessed after the textual cues had indicated high credibility. Moreover, people may use only a few cues to assess credibility, namely website suffix, author name, and advertisements. 
The results of this study offer several different insights to the study of information literacy, specifically web literacy. To begin, they tell us more about how specific cues contribute to credibility assessments online. While studies (Fogg, 2001; Fogg, Soohoo, \& Danielson, 2002) have indicated that people report high design quality as an important credibility determinant, the results of this study indicate that it was less important than traditional textual cues. The fact that there was a significant difference between textual and visual cues indicates that viewers were not analyzing websites indiscriminately. Different cues seem to carry different weight, and depending on the context, affect credibility in different ways.

There are also several possible explanations for why the participants would rate the high design quality webpage higher than the low design quality webpage in the high credibility group. Previous literature has indicated that visual appeal plays a large role in credibility (see Fogg, 2001; Fogg, et al., 2003). One reason may be that having a higher design quality could indicate to the viewer that the source has more resources at its disposal, such as money and staffing. This could connote legitimacy for the source. An organization with these resources may be seen as more invested in its enterprise and could have a higher stake in its audience's approval. The low design website, on the other hand, could connote that the website is made by a novice, or a group with very few resources.

The results also shed some light on the application of the Elaboration-Likelihood Model to web literacy. The model can help explain how the textual cues could be considered part of the central route, but the visual cues were part of the peripheral route. Because textual cues require the person to notice and read them, they require more processing. Also, despite the presumed low involvement with the subject of childhood illnesses, participants did take time to assess credibility on a more central route, indicating that low involvement does not necessarily mean careless credibility assessments. One possible explanation is that any health issue, regardless of involvement, may trigger more careful credibility assessments, but more research is needed to make this conclusion.

The fact that students were able to recall the presence or absence of the author's name and the website suffix one week later can also be accounted for by the ElaborationLikelihood Model, as Petty and Cacioppo argue that persuasion that occurs through the central route will be more enduring.

Another explanation for these results lies in the participants themselves. As current college students, these participants are most likely accustomed to a certain level of academic rigor. They have access to campus learning resources such as librarians, professors, and instructional materials which may emphasize information literacy (though it should be noted that none of the participants in this study were aware of having been taught information literacy specifically). This group of participants may be above-average critical informationseekers, and these information literacy skills could have been exhibited particularly because they were in a school setting.

All of these results are important because they indicate that college students are not only paying more attention to the websites they perceive as more credible but also credibility assessments could affect recall of content from articles. This shows that credibility is an important factor in finding information online, and that participants are motivated to use more credible information. 
An open-ended question at the end of the survey allowed participants to explain for themselves how they assess credibility online. Many reported that they look for both visual and textual cues. For example one participant stated, "...I take the title of the webpage and the format into consideration when assessing its validity." Participants also reported that their information-seeking skills vary depending on the purpose of their search. For example, "There is a difference in the type of websites that I use for inspiration, i.e. [sic] blogs or newspapers, in choosing a topic and others for more factual needs likes quotes and citations, i.e. [sic] non-profit websites or encyclopedias/academic journals. So maybe their credibility is viewed differently." While other participants held on to more traditional credibility beliefs: "Online texts, books, credible newspapers and magazines are okay to use, but things like blogs or personal websites have little credibility."

Interestingly, many participants mentioned a unique method of assessing credibility online, which is cross-referencing information. If a piece of information is found on more than one website it may indicate that the information is more likely true. One participant wrote, "I generally try to find information on two or more different websites. If I can find similar information on a more credible website then I may use information from a less credible website, but I always try to double check it with credible sources."

\section{CONCLUSION}

Credibility is an important aspect of accurate information, and having inaccurate information can be problematic in many ways. In the case of health information, credibility is especially important, as inaccurate information can lead to poor treatment, and this misinformation can then get repeated through other communication channels. As Pullum states, "Once the public has decided to accept something as an interesting fact, it becomes almost impossible to get the acceptance rescinded. The persistent interestingness and symbolic usefulness overrides any lack of factuality," (1991, p. 159).

This study examined information literacy, particularly web literacy in relation to seeking health information online. The cues that were used as credibility indicators for the websites, such as advertisements and author name, may have different effects when used on different kinds of websites. Furthermore, how people assess credibility when they hold more stake in the information may differ considerably. This study showed how one group of people applied information literacy skills online although this sample does not represent a broad range of education, nationality or age. Nonetheless, it provides an interesting snapshot into how credibility is negotiated online and suggests a complex system of evaluation being used. It is hoped that these results will provide a helpful context for librarians and teachers interested in helping students develop information and web literacy skills or for those working to revise and augment information literacy standards. Further research with groups of differing educational backgrounds, experience with online environments, and other backgrounds is important in order to understand how these skills vary for different groups and could contribute to the ongoing development of teaching materials for people working with those groups.

The abundance and diversity of information on the Web provides opportunities and challenges for the people using it. In order 
to seize those opportunities, users must be able to sift through that information with a critical eye. This study has attempted to contribute to the understanding of how people determine the trustworthiness of information sources online and how well they remember information they perceive as believable. Understanding the role that textual and visual cues play in this assessment has important implications for teachers, schools, students, parents, marketers, Web designers, policy makers, and anyone else concerned with fostering information literacy in the information society.

\section{ACKNOWLEDGMENTS}

The author would like to thank the students and staff at Georgetown University's Children's Digital Media Center, and its director, Dr. Sandra Calvert, for their extraordinary guidance and feedback on this research.

\section{REFERENCES}

Agosto, D. (2002). A model of young people's decision-making in using the Web. Library and Information Science Research, 24, 311--341.

Bird, N., McInerney, C. \& Mohr, S. (2010). Source evaluation and information literacy: Findings from a study on science websites. Communications in Information Literacy, 4 (2), 170.

Brem, S., Russell, J. \& Weems, L. (2001). Science on the Web: Students' evaluation of scientific arguments. Discourse Processes, $32,191--213$.

Burke, J. (2002). The internet reader. Educational Leadership, 60(3), 38-42.
Corrigan, R., \& Stephens, K. (2007). The effect of formal style and written medium type on message attitude and perceptions of sender's source credibility. Conference Papers: National Communication Association, Retrieved February 15, 2009, from Communication \& Mass Media Complete database.

Garner, S.D. (Ed.). (2005). Proceedings from High Level Colloquium on Information Literacy and Lifelong Learning. Alexandria, Egypt: Erlbaum.

Eastin, M. Mong-Shan, Y., Nathanson, A. (2006). Children of the net: Empirical exploration into the evaluation of internet content. Journal of Broadcasting \& Electronic Media, 50, 2, 211--230.

Fogg, B.J., Marshall, J., Laraki, O., Osipovich, A., Varma, C., Fang, N., et al. (2001). What makes Web sites credible?: A report on a large quantitative study. Proceedings of the SIGCHI Conference on Human Factors in Computing Systems, (pp.61-68). Seattle, Washington.

Fogg, B.J., Soohoo, C., Danielson, D., Marable, L., Stanford, J., \& Tauber, E. (2003). How do people evaluate a website's credibility?: Results from a large study. Paper presented at the Conference on Designing for User Experiences, New York, NY. Retrieved from http:// credibility.stanford.edu/publications.html.

Fox, J., Lang, A., Chung, Y., Lee, S., Schwartz, N., \& Potter, D. (2004). Picture this: Effects of graphics on the processing of television news. Journal of Broadcasting \& Electronic Media, 48(4), 646-674.

Freeman, K., \& Spyridakis, J. (2004). An examination of factors that affect the credibility of online health information. 
Technical Communication, 51(2), 239--263. Gunther, A. (1992). Biased press or biased public?: Attitudes toward media coverage of social groups. Public Opinion Quarterly, 56, 147--167.

Hamilton, M. \& Stewart, B. (1993). Extending an information processing model of language intensity effects. Communication Quarterly, 41, 231--46.

Hovland, C.I., Janis, I.L, \& Kelley, H. (1953). Communication and Persuasion. New Haven, CT: Yale University Press Jackson, L. (1992). Information complexity and medical communication: The effects of technical language and amount of information in a medical message. Health Communication, 4, 3, 197--210.

Johnson, T., Kaye, B. K., Bichard, S. L. \& Wong, W. J. (2008). Every blog has its day: Politically interested Internet users' perceptions of blog credibility. Journal of Computer-Mediated Communication, 13, $100-122$.

Karson, E., \& Korgaonkar, P. (2001). An experimental investigation of internet advertising and the Elaboration Likelihood Model. Journal of Current Issues \& Research in Advertising, 23(2), 53.

Kiousis, S. (2001). Public trust or mistrust? Perceptions of media credibility in the information age. Mass Communication \& Society, 4 (4), 381--403

Kools, M., Van de Wiel, M., Ruiter, R., \& Kok, G. (2006). Pictures and text in instructions for medical devices: Effects on recall and actual performance. Patient Education \& Counseling, 64(1--3), 104-111.

Kuiper, E., Volman, M., \& Terwel, J.
(2009). Developing web literacy in collaborative inquiry activities. Computers \& Education, 52(3), 668--680.

Livingstone, S., Bober, M. \& Helsper, E. (2005.) Internet literacy among children and young people: Findings from the UK Children Go Online project. London: LSE Research Online. Retrieved from: http:// eprints.1se.ac.uk/archive/00000397

Mark, A. (2011). Format as false judge of credibility: Messages from librarians and faculty and student responses. Communications in Information Literacy, 5 (1), 21-37.

McCrosky, J. (1969). A summary of the experimental research on the effects of evidence in persuasive communication. The Quarterly Journal of Speech, 55, 169--176. Moore, R., Stammerjohan, C., \& Coulter, R. (2005). Banner advertiser: Web site context congruity and color effects on attention and attitudes. Journal of Advertising, 34(2), 71-84.

Petty, R. E., \& Cacioppo, J. T. (1986). Communication and persuasion: Central and peripheral routes to attitude change. New York: Springer--Verlag.

Pew Internet \& American Life Project. (2001a). Pew Internet: Trend Data. Retrieved from http://pewinternet.org/Trend -Data/Online-Activites-Total.aspx on March 8, 2012.

Pew Internet \& American Life Project. (2011b). Pew Internet: Health. Retrieved from http://pewinternet.org/ Commentary/2011/November/Pew-InternetHealth.aspx on November 28, 2011.

Rains, S. A., \& Karmikel, C. D. (2009). Health information-seeking and perceptions 
of website credibility: Examining web-use orientation, message characteristics, and structural features of websites. Computers in Human Behavior, 25(2), 544--553.

Slater, M., \& Rouner, D. (1996). How message evaluation and source attributes may influence credibility assessment and belief change. Journalism \& Mass Communication Quarterly, 73(4), 974--991.

Sorapure, M., Inglesby, P. \& Yatchisin, G. (1998). Web literacy: Challenges and opportunities for research in a new medium. Computers and Composition, 15, 409-424

Stamm, K. \& Dube, R. (1994). The relationship of attitudinal components to trust in media. Communication Research, $21,105-123$

Van der Mole, J.W., \& Klijn, M. (2004). Recall of television versus print news: Retesting the semantic overlap hypothesis. Journal of Broadcasting \& Electronic Media, 48(1), 89--107.

Walther, J., Wang, Z. \& Loh, T. (2004). The effect of top-level domains and advertisements on health website credibility. Journal of Medical Internet Research, 6(3), 56--65. 